http://www.jfas.info

\title{
EMERGING HYBRID WIRE ELECTRO DISCHARGE TURNING FOR MICRO PARTS FABRICATION IN THE DEFENCE TECHNOLOGICAL AREA: A FEASIBILITY STUDY
}

\author{
R. Izamshah*, M. Akmal, M. S. Kasim and M. A. Ali \\ ${ }^{1}$ Precision Machining Group, Faculty of Manufacturing Engineering, Universiti Teknikal \\ Malaysia Melaka, 76100 Durian Tunggal, Melaka, Malaysia \\ ${ }^{2}$ Faculty of Manufacturing Engineering, Universiti Teknikal Malaysia Melaka, 76100 Durian \\ Tunggal, Melaka, Malaysia
}

Published online: 10 September 2017

\begin{abstract}
This study explores the feasibility of the hybrid wire electro discharge turning (HWEDT) process for the fabrication of micro components in the defence technological area. Only communication, surveillance and navigation technologies have clear developments for micro sized components that are mainly driven by advancements in micro sensors and microelectronics instruments. The rapid innovation in this sector contributes to the technological development of micro-satellites, micro-unmanned aerial vehicles ( $\mu$-UAV), micro-aerial vehicles (MAV) and micro-rockets with very complex components and tight specifications. From a manufacturing perspective, most of the devices in this sector require parts fabrication that is precise, complex and leaves no room for error in the manufacturing process; which is perfect for HWEDT.
\end{abstract}

Keywords: defence technology; surveillance technology; HWEDT; micro fabrication.

Author Correspondence, e-mail: izamshah@utem.edu.my

doi: http://dx.doi.org/10.4314/jfas.v9i3s.15 


\section{INTRODUCTION}

The military/defence field has been increasingly demanding miniature devices and components with complex micro-dimension features made from various materials. Concomitant technology in the miniature sensors and electronic devices embodied by micro-manufacturing has become one the key sectors in military/defence field. Emerging micro-manufacturing in this field contributes to greater precision, complex geometric features and tight tolerances which extend the capabilities of miniaturization in the mechanical parts for which the most micro-manufacturing is required. Critical components used in the defence technological area can be very complex and require tight specifications. For example, a $0.0001 \mathrm{~mm}$ deviation in the military vision component can cause a weapon carried by a soldier or mounted to a tank to miss a far-off target.

The rapid development and advancements in the sensors and electronics field has driven the modernization of the defence technological area in the application of miniaturized devices and components. The need for sensors and electronics advancement initiated micro-manufacturing in the defence and military field. In the defence technological area, component miniaturization is mostly concentrated in the fields of communication, surveillance and navigation technologies, sensors and electronics, defence mobility and platforms, weapons and ammunition, biomedical engineering, aerospace and nuclear technology as depicted in Fig. $1[1-11]$.

Among these sectors, only communication, surveillance and navigation technologies have clear need for micro-manufacturing considering an integration with both micro systems and instruments. Rapid innovation in this sector contributes to the technological development of micro-satellites, micro-unmanned aerial vehicles ( $\mu$-UAV), micro aerial vehicle (MAV), micro-underwater vehicle ( $\mu$-UV) and micro rockets with very complex components and tight specifications.

From a manufacturing perspective, most devices in this sector require part fabrication that contains micro dimensional aspects assembled with others microelectronics systems such as thrusters, propulsions, valves and actuators on a micro scale (Fig. 2 and Fig. 3). The size of the combustion engine for the thrusters that are employed for micro satellite and MAV are in 
the range between $1-1000 \mu \mathrm{m}$.

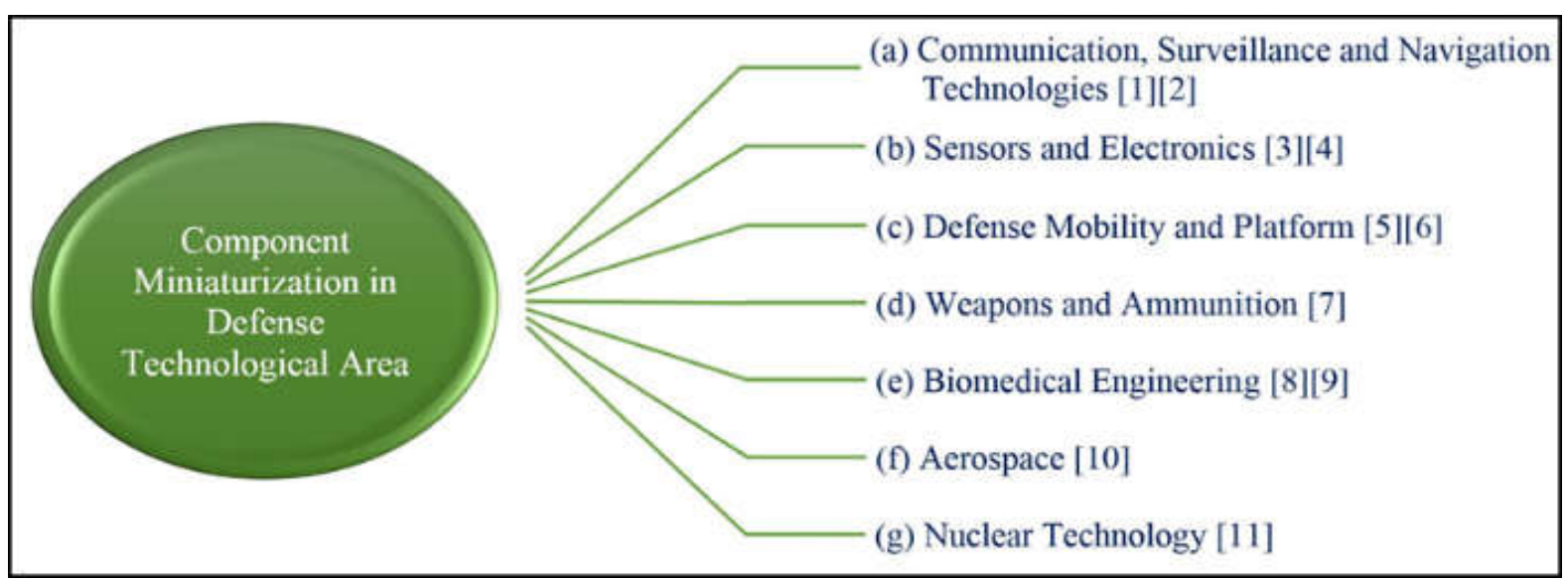

Fig.1. Application of miniature components in defence technological sectors

The development of the powerful combustion-based micro-thrusters is crucial in the application of micro-satellites and MAV due the limitations of the battery-based thruster, solid rocket and catalytic monopropellant which produce impulses and have an extremely low thrust [12]. As a matter of fact, micro-satellite thrusters for stations require a small thrust $(1-1000 \mathrm{mN})$ and a highly specific impulse (250-450s) with a small impulse bit ( 1-5 Ns) for an operational period year [13].

Generally, micro-dimension features in this sector are fabricated by processes that are categorized into scaling up nano-scale processes or scaling down the conventional processes. Between these two categories, scaling down the conventional process is more preferable because of the competitive costs and production time. However, the limited flexibility of this process to form intricate shapes on both macro and micro dimensional scales limits its usage. Therefore, this paper presents an experimental study to demonstrate the capabilities of the HWEDT process in the fabrication of free-form geometric features with macro and micro dimensions and its ability to apply miniaturization to the defence technological area. Incorporating wire electrical discharge machining (WEDM) to turn tiny cylindrical parts presents its own set of challenges, which will be addressed in this research. Some possible factors that will be discovered are the principle movements of a thin single-strand wire on a rotating workpiece, which carried away by rotational motion produced by additional rotary mechanisms. This paper includes a review on challenges in manufacturing micro scale components, HWEDT working principles and experimentation with HWEDT performance. 


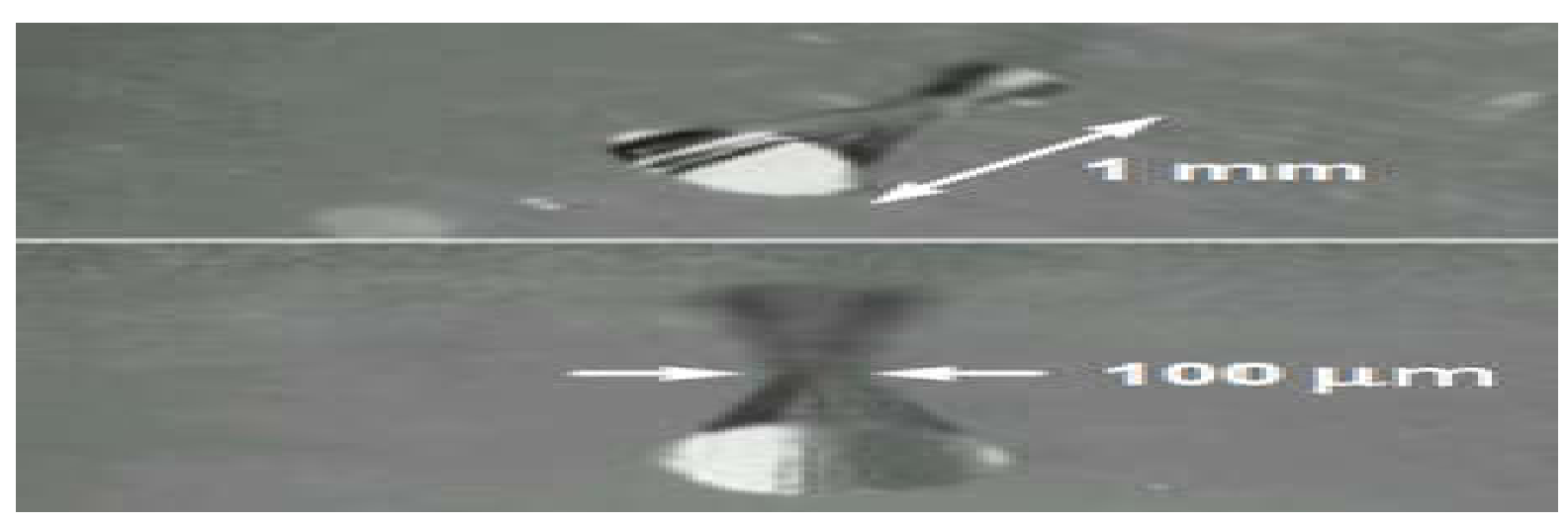

Fig.2. Image of a micro valve with a throat diameter of $100 \mu \mathrm{m}$ [14]

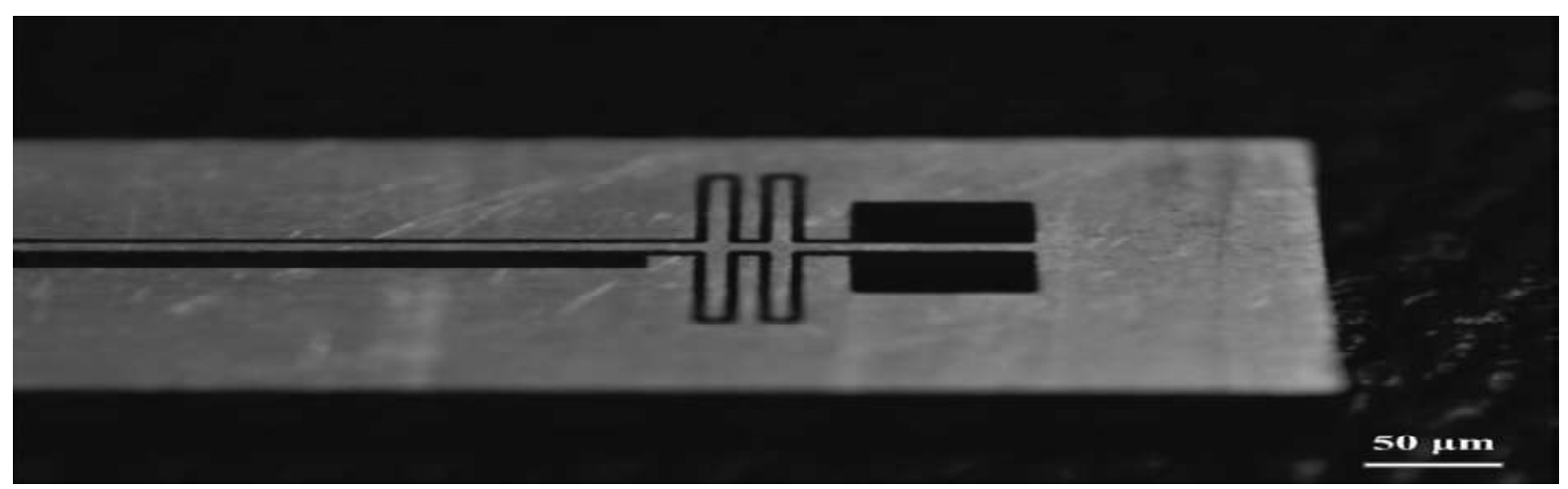

Fig.3. Image of a micro actuator [15]

\section{EXPERIMENTAL}

Various manufacturing processes have the capability to produce micro parts and the number has been continuously increasing recently as hybrid processes are developed. The restrictions on established processes include complex geometries, wide range materials and high relative accuracy, which mean that the traditional stand-alone process needs to be integrated with two or more processes that operate individually on the machine or merely assisted during machining [16-17]. The common fabrication techniques used in developing micro structures can be categorized into two types that are scaling up nano-scale processes [18] using silicon-based technology and scaling down, which employs the conventional manufacturing processes. Between these two categories, conventional manufacturing processes such as micro milling for the three-dimensional part profile, micro turning for the cylindrical part profile, micro EDM for the three-dimensional part profile and micro grinding for surface modification are more favourable due to their flexibility, reliability and economical nature.

However, scaling down processes create several challenges especially on the process stability 
and the behaviour of the materials due to the dynamic of material removal process. This is especially problematic for thin, tiny, difficult-to-machine materials [19-20]. In addition, most micro machining machines are designed for specific profile geometry fabrication. Table 1 depicts the machining capabilities of each micro machining technique and their mechanic of material removal process.

Table 1. Comparison between micromachining techniques [21]

\begin{tabular}{ccc}
\hline Type & Machining Profile & Mechanic Material Removal Process \\
\hline Micro milling & Three-dimensional part profile & Physical contact between tool and workpiece \\
Micro turning & Cylindrical part profile & Physical contact between tool and workpiece \\
Micro EDM & Three-dimensional part profile & No physical contact between tool and workpiece \\
Micro grinding & Surface modification & Physical contact between tool and workpiece \\
\hline
\end{tabular}

On most micro machining processes, cutting forces is one of the greatest challenges. The forces exerted on the machine reduce the machining accuracy and limits the machinable size dimensions [21]. Moreover, due to the lack rigidity in the micro part feature, deflection is more likely to occur, leading to dimensional surface errors. The cutting force is a major problem because the part deflection limits the capability of the micro machining technique. Fig. 4 shows the mechanical material removal process associated with part deflection in the micro turning process. Therefore, a suitable material removal process for fabricating the micro cylindrical parts is necessary for overcoming the part deflection problem.

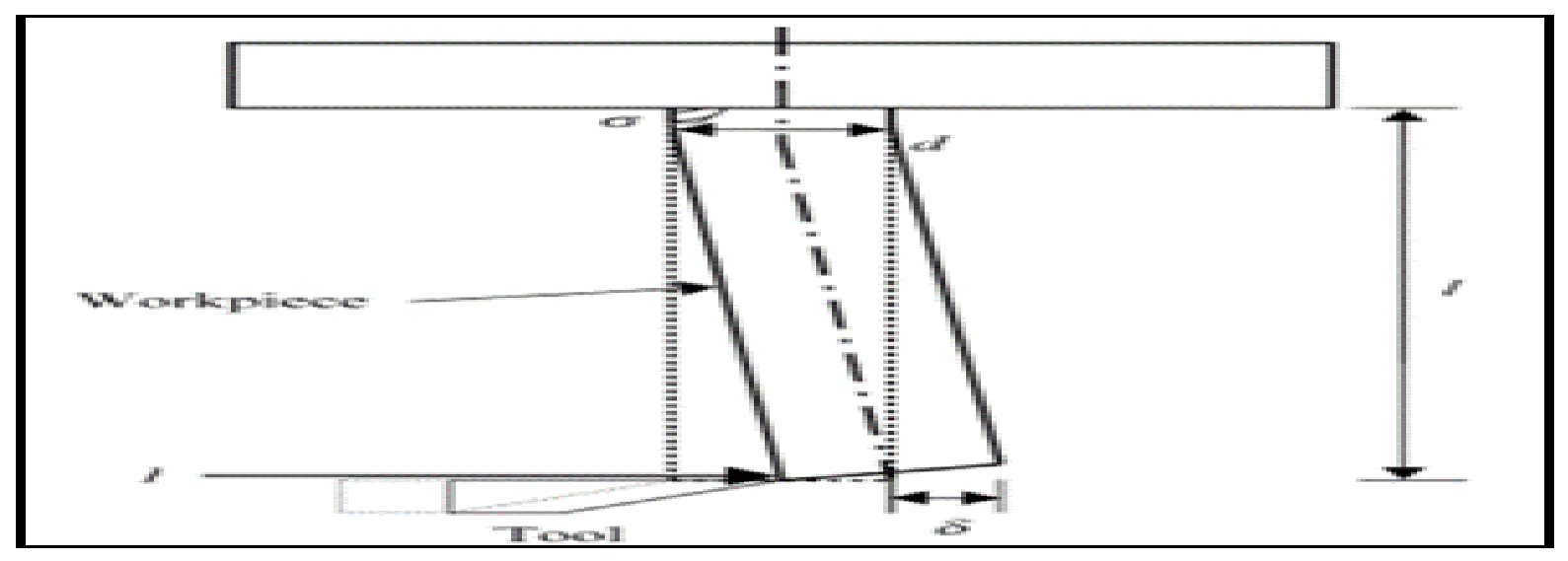

Fig.4. Workpiece deflection in the micro turning process

One of the most suitable candidates is WEDM, in which the materials are removed using an electrical discharge of energy without a physical contact among the tools and workpieces, 
minimizing the cutting forces [22]. By utilizing the electrical discharge sparking phenomenon in removing materials, difficult-to-machine materials such as titanium alloys which typically encounter conflict in conventional machining are no longer an issue in electrical-discharge-based machining [23].

Employing the electrical discharge machining (EDM) process in the production of miniature devices and tiny components is important in defence applications such as the electrostatic micro actuator, which is fabricated by [24]. The EDM-based process has promising ability to produce precise and complex parts such as the micro-air journal, which was successfully fabricated by [25] in the application of the micro-gas turbine engine by a small micro electrode wire $(\varnothing 30 \mu \mathrm{m})$.

Incorporating the WEDM process and turning the workpiece is beneficial in countering part deflection. WEDM uses a fine metallic wire which carries the discharged energy and continuously feeds from a spool, keeping a constant diameter. Hence, combining the EDM process with a rotating workpiece can provide an effective solution for fabricating parts with complex geometrical features made from materials like tungsten carbide, tool steel, titanium alloys and memory shape alloys which known as a difficult-to-machine material.

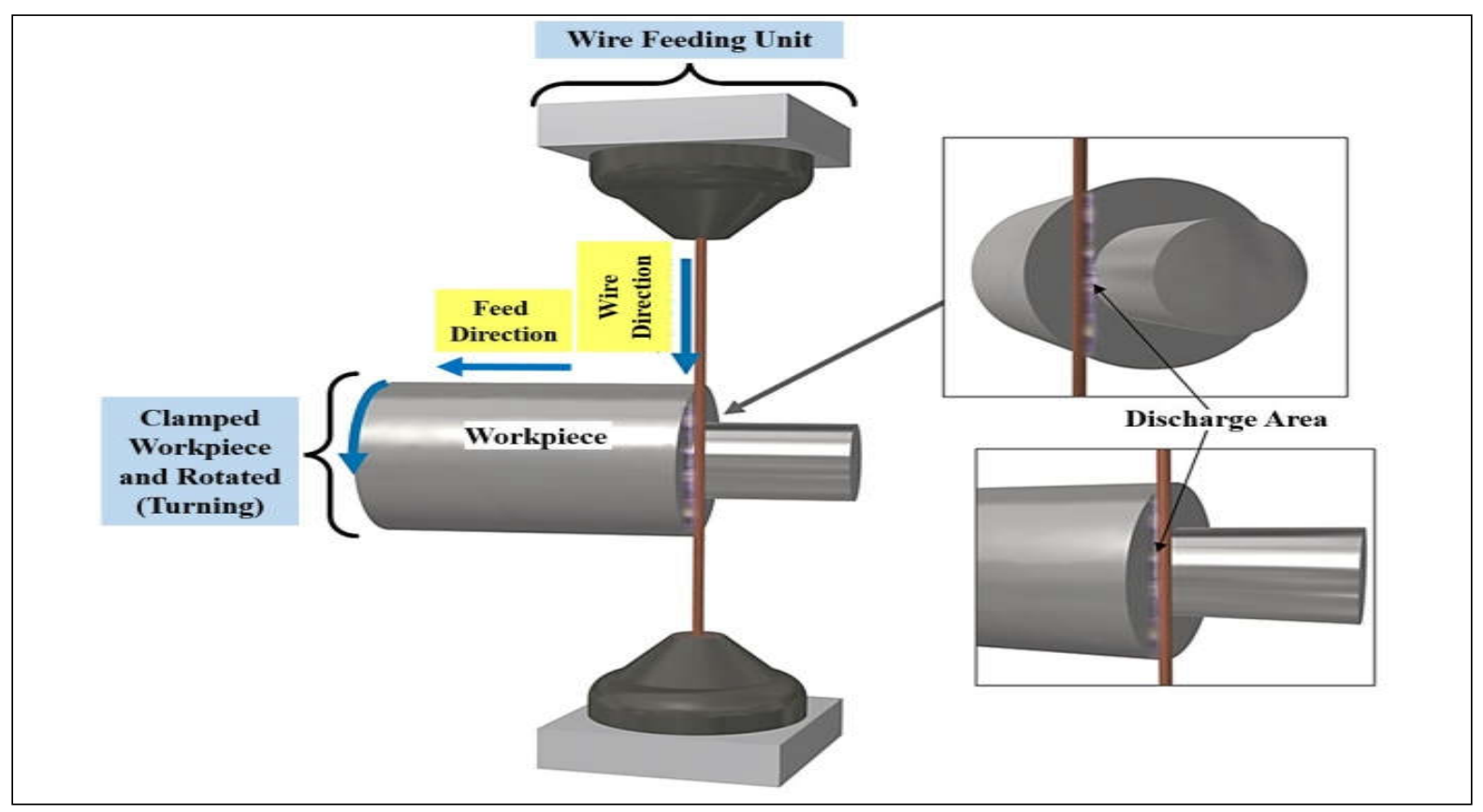

Fig.5. The HWEDT working principle

The principles of the HWEDT process (Fig. 5 and Fig. 6) involve discharging an energy spark between a continuous wire and the workpiece. In HWEDT, the original form of the 
workpieces does not need to be in cylindrical form or macro-sized in diameter. The arrangement between the rotating electrical conductor workpiece and motion of a thin electrode wire accentuate an opportunity in producing complex and hardened cylindrical components which is currently limited by conventional processes.

In order to constantly feed the electrode wire into the machining gap to perform the erosion process, the linear motion in the $\mathrm{x}-\mathrm{y}$ direction is driven and controlled by the servo mechanism. The retention wire spool is also important for ensuring that constant tension is applied during the erosion process. In promising stability sparking, the flushing method is applied through a high pressure water jet to enhance the material removal rate (MRR) and surface finish as well as maintain a uniform thermo-environment.

In the spark erosion state, as soon as the material is eroded by the earliest spark, the machining gap distance spaced away make room for high pressure water jet to flush away the excess melted material/ debris. Then, the machining gap is closed again through the mechanism wire spooler, servo feed, and rotary mechanism. The electrode wire is continuously replenished in order to ensure that the fresh electrode wire surface will be available for the next sparks. By applying the rotary mechanism, the un-machined portion of the workpiece surface is replaced by the machined portion, and vice versa. The machined portion, which was previously exposed to sparks erosion, is now open for a second flushing to remove the excessive debris.

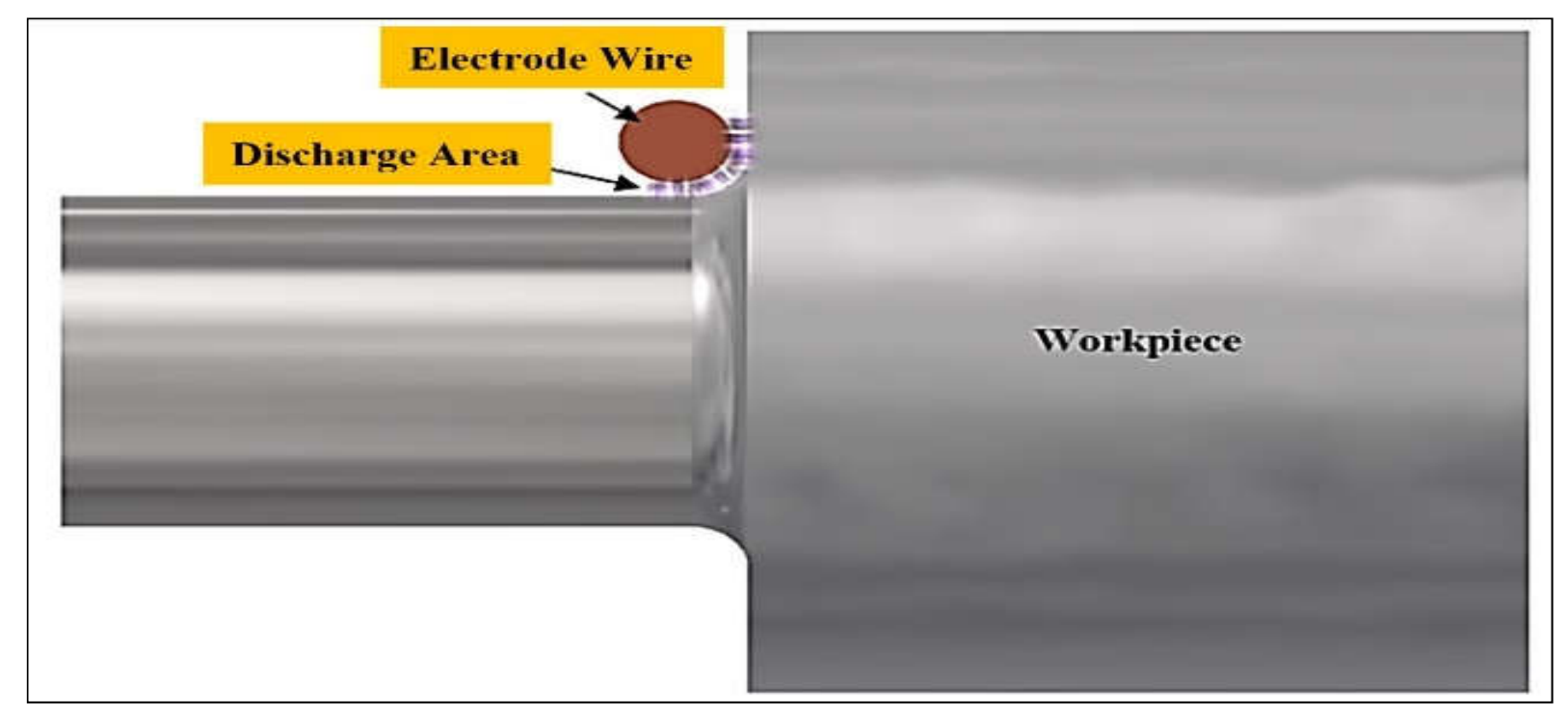

Fig.6. The phenomena discharge area in HWEDT along the electrode wire 


\section{RESULTS AND DISCUSSION}

By means of erosion, the performance of the HWEDT recognized as a process that generate the minimum value of the mechanical force which useful for parts fabrication in micro-dimension without damaging the parts. Poor dimensional accuracy occurs in the conventional process and includes micro-turning implications from parts deflection because of the reduction in rigidity during machining [26].

In this study, the experimental were conducted and compared between two type processes which are micro turning and HWEDT in fabricates two categorized materials which were low and high strength in mechanical properties. Performance HWEDT is evaluated on brass (low strength) and Ti6Al4V (high strength) as materials and compared to the micro turning process which conducted by [26]. Selection of Ti6Al4V as material, due its wide use in aerospace and defence applications, besides being well-known with poor machinability characteristics [27-28]. Ti6A14V also possesses excellent mechanical properties as required for structural efficiency in surgical and dental implants. Undoubtedly, it has become the primary choice in orthopedic applications because of its mechanical and tribological characteristics that are compatible with bone characteristics [29].

The results of the experiment indicate that straight cylindrical geometry can be successfully fabricated with as much as $250 \mu \mathrm{m}-300 \mu \mathrm{m}$ in diameter and an error deviated less than $7 \mu \mathrm{m}$ (Table 2). Table 2 shows the performance of HWEDT in producing final diameter micro parts that are bigger than those produced in micro turning. On the other hand, HWEDT shows a better aspect ratio (length-to-diameter) which is approximately three times larger than the aspect ratio of the micro-turning process. Fig. 7 shows the fabricated parts in straight turning with a $250 \mu \mathrm{m}$ diameter when Ti6Al4V materials are used.

Table 2. Dimensional accuracy of HEWDT

\begin{tabular}{ccc}
\hline \multirow{2}{*}{ Design Dimension $(\boldsymbol{\mu m})$} & \multicolumn{2}{c}{ Dimensional Accuracy } \\
& Measured Dimension $(\boldsymbol{\mu m})$ & Error $(\boldsymbol{\mu m})$ \\
\hline 250 & 253.72 & 3.72 \\
300 & 306.32 & 6.32 \\
\hline
\end{tabular}


Table 3. Comparison of the length to diameter ratio (L/D) between HWEDT and the micro turning process

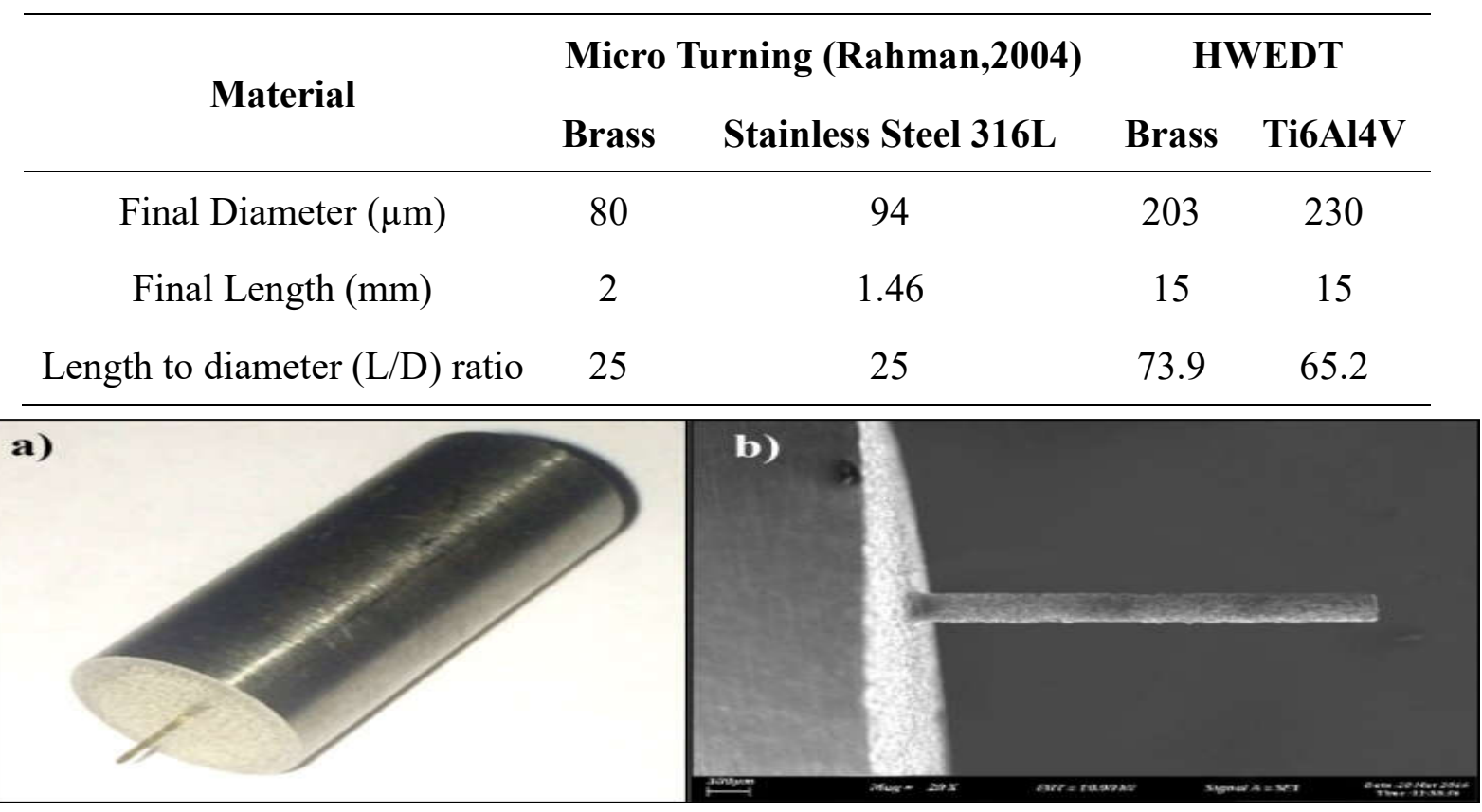

Fig.7. A $250 \mu \mathrm{m}$ straight cylindrical part fabricated by HWEDT (a) actual part (b) SEM micrograph

By employing electrode wires in the range of $200 \mu \mathrm{m}$ to $500 \mu \mathrm{m}$ in the common HWEDT process, the HWEDT process becomes suited for producing micro dimension profiles especially in the slitting process because of the micro scale size of the electrode wire. Fig. 8 shows the capability of HWEDT to fabricate free-form geometries that contain dimensions for both macro and micro scales.

There are four types of geometric features that were evaluated using the process with a single pass cutting approach used to yield the effective machining cost. The free-form geometric contains shapes like dovetails, which look like micro-valves, and others shape like cones, ellipses and grooves. The machine successfully reduced the diameter from $9.49 \mathrm{~mm}$ to a micro size dovetail shape Ti6A14V which included a throat (bottom side) dimension of 163 $\mu \mathrm{m}$ and top that was $372 \mu \mathrm{m}$ in diameter. 


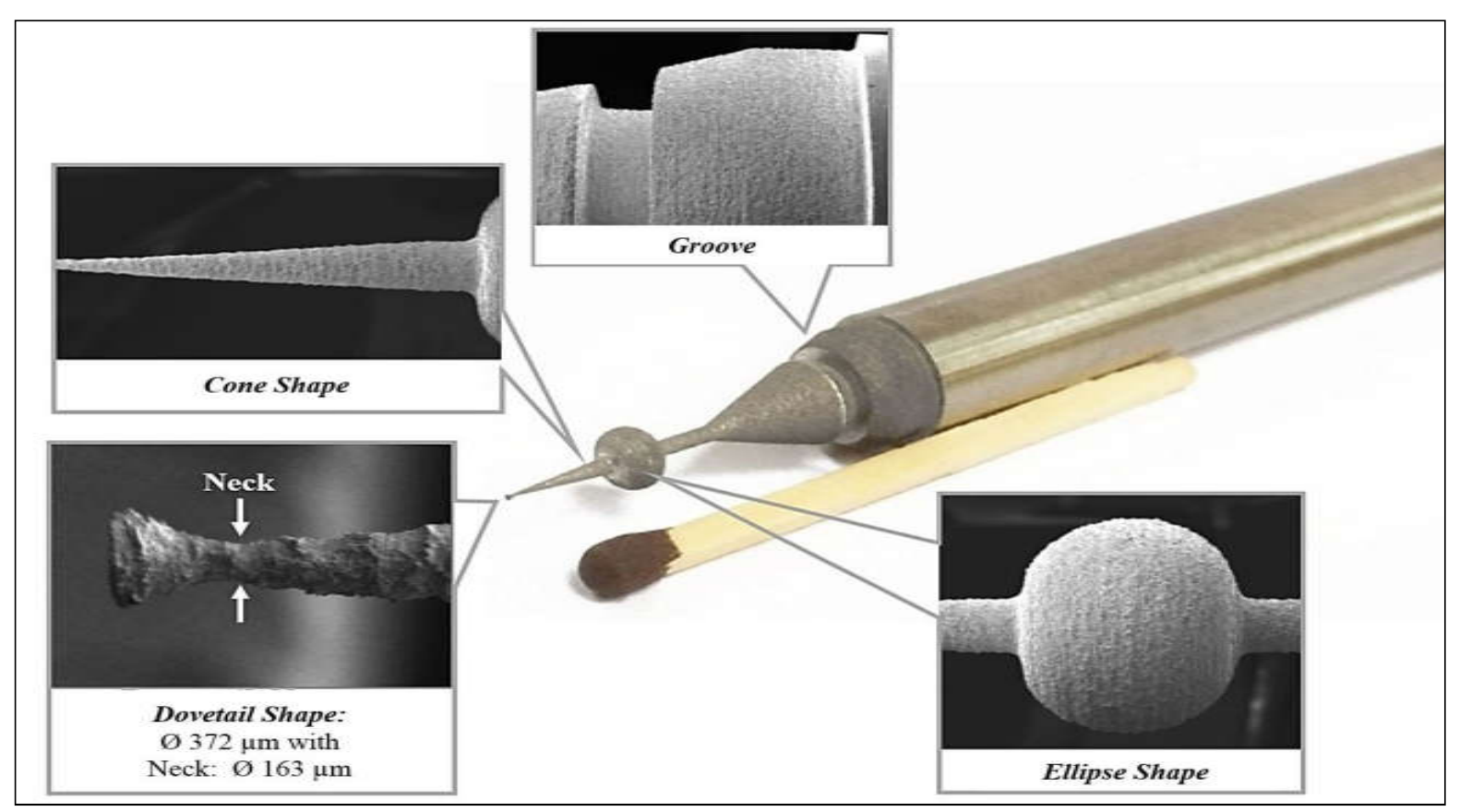

Fig.8. Different geometries for evaluating machining capability

\section{CONCLUSION}

In this work, a feasibility study analyzing HWEDT as an alternative microfabrication process for the miniaturization of the defence application has been conducted and following conclusions can be drawn:

- The modernization of micro parts in the defence technological area is clearly driven by sensors and electronics advancement focused in the sectors of communication, surveillance and navigation technologies.

- HWEDT solves the problems associated with the existence of the micro machining machine. It allows for the fabrication of parts with complex geometrical features made from difficult-to-machine materials. These parts have tight details and tolerances, which are inaccessible to down-scale processes because of aspect process stability and the mechanic material removal process.

- HWEDT employs EDM-based fine metallic electrode wires that are continuously fed to a rotating workpiece. The materials are remove using an electrical discharge energy without physical contact between tools and workpieces, minimizing the cutting forces which are the main problems associated with the fabrication of micro parts.

The experimentation revealed the capabilities of HWEDT in the fabrication of micro 
dimension parts which include ensuring the accuracy of the finest parts, the aspect ratio, free-form geometries and the interblend dimension between macro and micro for the turning and slitting process. The consistent stability of the HWEDT process delivers success in micro manufacturing which suits the miniaturization of the defence technological area.

\section{ACKNOWLEDGEMENTS}

The research work was financial supported through Ministry of Higher Education research grant [grant numbers: FRGS/2/2014/TK01/UTEM/03/2]. Appreciation is also expressed to the Universiti Teknikal Malaysia Melaka for supporting this study (UTeM MyBrain Schorlaship). The authors are thankful to all technical staffs, Advanced Manufacturing Centre of Faculty Manufacturing Engineering for providing the necessary facilities, constant guidance and encouragement.

\section{REFERENCES}

[1] Zencik R G, Kohlhepp K. GPS micro navigation and communication system for clusters of micro and nanosatellites. In IEEE Aerospace Conference, 2001, pp. 2515-2522

[2] Jahangir M, Baker C. Robust detection of micro-UAS drones with L-band 3-D holographic radar. In IEEE Sensor Signal Processing for Defence, 2016, pp. 1-5

[3] Nie W, Xi Z, Xue W, Zhou Z. Study on inertial response performance of a micro electrical switch for fuze. Defence Technology, 2013, 9(4):187-192

[4] Schultz G, Mhaskar R, Prouty M, Miller J. Integration of micro-fabricated atomic magnetometers on military systems. In SPIE Defense+Security, 2016, pp. 10-18

[5] Schultz G, Shah V, Miller J. Applications of miniaturized atomic magnetic sensors in military systems. New Hampshire: White River Technologies Inc., 2012

[6] Biao W, Chao L, Zhihui Z, Qingjun Z. DOA estimation based on compressive sensing method in micro underwater location platform. Applied Mathematics and Information Sciences, 2015, 1565(3):1557-1565

[7] Wang W, Liu W G, Zou J L, Huo P F. A MEMS safe and arm device for spin stabilized ammunition fuze. Advanced Materials Research, 2011, 403:4593-4597

[8] Saccomandi P, Schena E, Oddo C M, Zollo L, Silvestri S, Guglielmelli E. Microfabricated 
tactile sensors for biomedical applications: A review. Biosensors, 2014, 4(4):422-448

[9] Maeng J, Meng C, Irazoqui P P. Wafer-scale integrated micro-supercapacitors on an ultrathin and highly flexible biomedical platform. Biomedical Microdevices, 2015, 17(1):11-20

[10] Wang J X, Qian X M. Application and development of MEMS in the field of aerospace. Applied Mechanics and Materials, 2014, 643:72-76

[11] Bhandaru S, Hu S, Fleetwood D M, Weiss S M. Total ionizing dose effects on silicon ring resonators. IEEE Transactions on Nuclear Science, 2015, 62(1):323-328

[12] Ju Y, Maruta K. Microscale combustion: Technology development and fundamental research. Progress in Energy and Combustion Science, 2011, 37(6):669-715

[13] Yetter R A, Yang V, Wu M H, Wang Y, Milius D, Aksay I A, Dryer F L. Combustion issues and approaches for chemical microthrusters. International Journal of Energetic Materials and Chemical Propulsion, 2007, 6(4):32-41

[14] Janson S W, Helvajian H, Hansen W W, Lodmell J. Microthrusters for nanosatellites. In 2nd International Conference on Integrated Micro Nanotechnology for Space Applications, 1999, pp. 1-17

[15] Chen Z. Analysis and test of a new MEMS micro-actuator. Microsystem Technologies, 2016, 22(5):943-952

[16] Chavoshi S Z, Luo X. Hybrid micro-machining processes: A review. Precision Engineering, 2015, 41:1-23

[17] [Aspinwall D K, DewesR C, Burrows J M, Pa M A. Hybrid high speed machining (HSM): System design and experimental results for grinding/HSM and EDM/HSM. CIRP Annals-Manufacturing Technology, 2001, 50(1):145-148.

[18] Kaur I, Yadav S, Singh S, Kumar V, Arora S, Bhatnagar D. Nano electronics: A new era of devices. Solid State Phenomena, 2015, 222:99-116

[19] Hadzley A B M, Izamshah R, Sarah A S, Fatin M N. Finite element model of machining with high pressure coolant for Ti-6Al-4V alloy. Procedia Engineering, 2013, 53:624-631

[20] Izamshah R A, Mo J P T, Ding S L. Finite element analysis of machining thin-wall parts. Key Engineering Materials, 2010, 458(45):283-288 
[21] Uhlmann E, Mullany B, Biermann D, Rajurkar K P, Hausotte T, Brinksmeier E. Process chains for high-precision components with micro-scale features. CIRP Annals-Manufacturing Technology, 2016, 65(2):549-572

[22] Ali M A, Hussein N I S, Rizal S M, Izamshah R, Hadzley A B M, Kasim M S, Amri S M, Subramonian S. The effect of EDM Die-sinking parameters on material removal rate of beryllium copper using full factorial method. Middle-East Journal of Scientific Research, $2013,16(1): 44-50$

[23] Suresh S, Jamil M A, Sulaiman S, Shokor M R M. Optimization of electrode material for EDM die-sinking of titanium alloy grade 5-Ti6Al4V. International Journal on Advanced Science, Engineering and Information Technology, 2016, 6(4):534-539

[24] Bhuiyan M, Shihab B. Development of copper based miniature electrostatic actuator using WEDM with low actuation voltage. Microsystem Technologies, 2014, 22(12):2749-2756

[25] Wang Y K, Zeng Z Q, Wang Z L, He X L. Design and fabrication of an aerodynamic micro-air journal bearing using micro-wire electrical discharge machining. Key Engineering Materials, 2013, 562:8-12

[26] Rahman M A. CNC microturning: An application to miniaturization. National University of Singapore, 2004

[27] Ding S L, Izamshah R A, Mo J, Zhu Y W. Chatter detection in high speed machining of titanium alloys. Key Engineering Materials, 2011, 458:289-294

[28] Izamshah R, Yuhazri M Y, Hadzley M, Ali M A, Subramonian S. Effects of end mill helix angle on accuracy for machining thin-rib aerospace component. Applied Mechanics and Materials, 2013, 315:773-777

[29] Ajiz A, Affi J. The effects of short-time solution treatment and short-time aging on mechanical properties of Ti-6Al-4V for orthopaedic applications. International Journal on Advanced Science, Engineering and Information Technology, 2015, 5(4):329-334

\section{How to cite this article:}

Izamshah R, Akmal M, Kasim MS, Ali MA. Emerging hybrid wire electro discharge turning for micro parts fabrication in the defence technological area: a feasibility study. J. Fundam. Appl. Sci., 2017, 9(3S), 176-188. 